\title{
Improved Remotely Sensed Satellite Products for Studying Lake Victoria's Water Storage Changes
}

\author{
M. Khaki ${ }^{\mathrm{a}, 1}$, J. Awange ${ }^{\mathrm{b}}$ \\ ${ }^{a}$ School of Engineering, University of Newcastle, Callaghan, New South Wales, Australia. \\ ${ }^{b}$ School of Earth and Planetary Sciences, Discipline of Spatial Sciences, Curtin University, Perth, Australia.
}

\section{Abstract}

\section{Hydroclimate}

\footnotetext{
Email address: Mehdi.Khaki@newcastle.edu.au (M. Khaki)

${ }^{1}$ Contact details: School of Engineering, University of Newcastle, Callaghan, New South Wales, Australia, Email: Mehdi.Khaki@newcastle.edu.au, Tel: +61410620379
} 


\section{Introduction}

Lake Victoria, spanning an area of $68,800 \mathrm{~km}^{2}$ with a basin size of more than $252,000 \mathrm{~km}^{2}$ (e.g., Onganga and Awange, 2005), is the largest lake in the developing world, and the world's second largest freshwater lake after Lake Superior in the US. The lake, which is shared by Kenya, Tanzania, and Uganda directly supports the livelihood of more than 42 million people, with the population projected to triple by 2050, (see e.g., Okungu et al., 2005; Bremner et al., 2013). Furthermore, being the source of the White Nile, i.e., one of the main streams of the Nile river, the lake supports the livelihood of Egypt, Sudan and South Sudan (e.g., Awange et al., 2014). Moreover, it is known to modulate the regional climate (e.g., Nicholson et al., 2003; Awange et al., 2013a). Any significant change in the lake water storage, triggered e.g., by climatic impacts (e.g., Yin and Nicholson, 1998; Conway, 2002; Omondi et al., 2014) or anthropogenic factors such as dam expansion (e.g., Consulate, 2012; Aman, 2014), therefore, is likely to affect millions of people who directly depend on it for livelihood plus others the world over who indirectly depend on it. Therefore, it is essential to continuously monitor its behaviour in terms of water storage changes and effective climate parameters as undertaken, e.g., by Awange et al. (2008) and Swenson and Wahr (2009) among others.

Its monitoring has often taken on various forms, e.g., use of ground-based in-situ measurements (e.g., Njuru, 2002; Mugidde et al., 2003), land surface models (LSM; e.g., Khan et al., 2011; Chamberlain et al., 2014), and satellite remote sensing products (see, e.g., Piper et al., 1986; Woodward and Warren, 2007; Song et al., 2015; Crataux et al., 2016; Sichangi and Makokha, 2017; Anyah et al., 2018). Due to its wide area and limited number of in-situ stations (e.g., rain and water level gauges), monitoring of the lake solely based on ground-based measurements, i.e., "boots on the ground", becomes practically impossible. Moreover, there is no reliable regional land hydrological model in the area for undertaking such monitoring. Satellite remote sensing, on the other hand, due to their vast coverage, high spatio-temporal resolutions, and easier access provide better tools for analyzing the hydroclimate variations within Lake Victoria Basin (LVB).

A number of literature have studied Lake Victoria using various satellite remotely sensed products, e.g., satellite radar altimetry to observe the lake's water level variations (e.g., Awange et al., 2013b; Uebbing et al., 2015; Sichangi and Makokha, 2017) and their importance for flood monitoring (Birkett et al., 1999), the Gravity Recovery and Climate Experiment (GRACE) for studying the lake's total water storage (TWS) changes (e.g., Awange et al., 2008, 2014; 
Hassan and Jin, 2004), satellite precipitation data for studying the lake's rainfall (e.g., Kizza et al., 2009; Awange et al., 2013b), a combination of both ground-based and remotely sensed observations for studying the lake's water balance (e.g., Yin and Nicholson, 1998; Swenson and Wahr, 2009). Despite this plethora of studies, a precise study of the hydrological processes of Lake Victoria using merged and improved coherent datasets from multiple sources, what would also benefit other inland lake waters the world over, is still missing. For example, although Khaki et al. (2018a) used a multi-mission satellite data to study various water storage including surface and sub-surface water components over the Nile basin, their study does not account for the discrepancy between different datasets from various sources. It is also important to further study the water storage changes within the water balance equation to analyze the interrelationship between the different water components.

Due to the fast emerging satellite platforms, especially in the last two decades, there are different data sources for various data types, making the extraction of the most reliable datasets from the available products, e.g., a merged and improved rainfall data from various precipitation sources, a necessity for providing improved datasets. Moreover, the balance between different data types (i.e., precipitation, evaporation, water storage changes, and water discharge) that is normally addressed using the water balance equation stands to benefit from using such merged and improved datasets. Traditionally, hydrological model and data assimilation are used to establish the balance between different components (e.g., Pan and Wood, 2006; Sahoo et al., 2011; Pan et al., 2012; Khaki et al., 2017a, 2018b). Here, however, in the absence of an accurate model over the LVB, use is made of a data combination strategy to obtain a coherent data set of four water cycle components, i.e., precipitation $(\mathbf{p})$, evaporation $(\mathbf{e})$, water storage changes $(\Delta \mathbf{s})$, and discharge $(\mathbf{q})$. This could enable one to accurately analyze the lake's hydrology and the associated climatic variation/change impacts. The main objectives of the present contribution, therefore, are (i) generate improved coherent water cycle components ( $\mathbf{p}, \mathbf{e}, \Delta \mathbf{s}$ and q) from different sources over lake Victoria, (ii) explore the changes in the lake's water storage and its water level using these improved coherent datasets, and (iii) investigate climatic impacts on the lake's water storage changes based on the improved datasets in (i). To achieve these goals, this study aims at using a proposed two-step filtering step by Aires (2014). The filter applies a Simple Weighted (SW) approach to merge remotely sensed products over Lake Victoria from multi-mission satellites and filter them employing a Postprocessing Filter (PF) to generate improved coherent products of precipitation (p), evaporation (e), water storage 
changes $(\Delta \mathbf{s})$, and discharge $(\mathbf{q})$ by accounting for balance between them. These improved products are useful in not only analysing changes of the lake as a consequence of climate and anthropogenic impacts but also in correcting for the imbalance in the components of the water balance model $(\Delta \mathbf{s}=\mathbf{p}-\mathbf{e}-\mathbf{q})$. This procedure for improving remotely sensed data could potentially be applied to any inland lake of basin scale around the world.

Multi-mission satellite and ground-based products used includse three precipitation products of Tropical Rainfall Measuring Mission Project (TRMM; TRMM, 2011), Global Precipitation Climatology Centre (GPCC; Schneider et al., 2008), and Climate Prediction Center (CPC) unified gauge dataset (Chen et al., 2002). For evaporation, three data products of MODIS (Moderate Resolution Imaging Spectroradiometer) Global Evapotranspiration Project (MOD16; Mu et al., 2007), Global Land Evaporation Amsterdam Model (GLEAM; Miralles et al., 2011), and ERA-interim (Simmons et al., 2007) are employed. Water storage changes from GRACE and water discharge time series from two ground stations (Jinja and Entebbe) are also used. In addition, satellite altimetry data from TOPEX/Poseidon (T/P) and its follow-on missions Jason-1 and -2, as well as ENVISAT (Environmental Satellite) are applied for the analysis of surface water variations. The altimetry data are used to build virtual stations covering the period from 1992 to 2016 over Lake Victoria (Figure 1). Lake level variations at virtual stations, and associated precipitation and TWS time series are used to analyze the Lake Victoria behaviors during the study period. To improve on the satellite altimetry range estimations, which are erroneous when used over an inland body of waters and rivers (Birkett et al., 1999; Calmant et al., 2008; Khaki et al., 2015), the Extrema Retracking (ExtR) algorithm of Khaki et al. (2014) is employed to retrack satellite waveform data. Furthermore, principal component analysis (PCA Lorenz, 1956; Preisendorfer, 1988) is used to better investigate spatio-temporal variations of Lake Victoria water storage and its relationship to climatic impacts.

The remainder of the study is organised as follows. In Section 2 datasets are presented while Section 3 provides the method. The results and discussion are presented in Section 4, and the study concluded in Section 5

\section{Data set}

\section{1. $G R A C E$}

Monthly GRACE level 2 (L2) potential coefficients products up to degree and order (d/o) 90 are obtained for the period 2002-2016 from the ITSG-Grace2014 gravity field model 


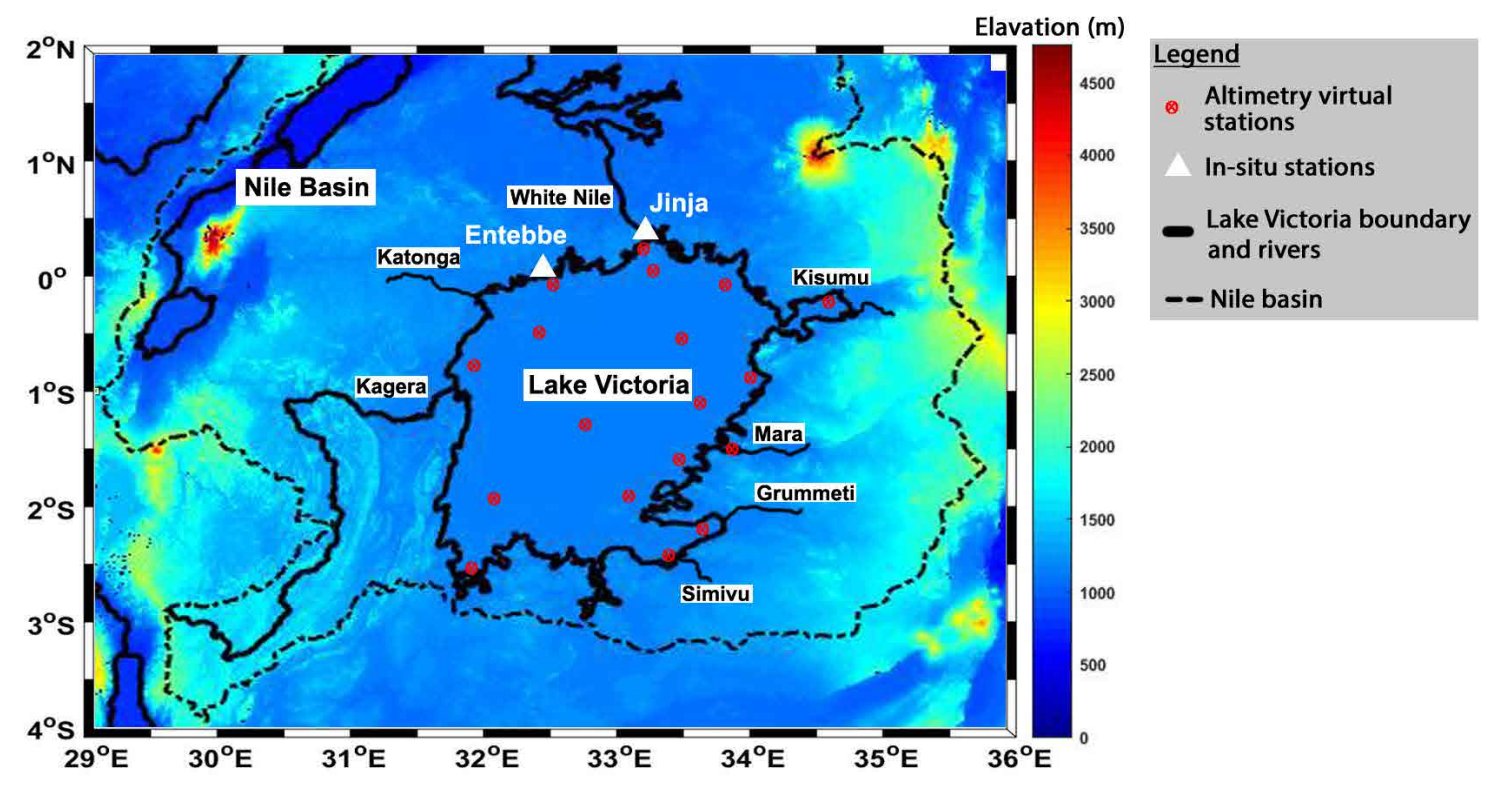

Figure 1: Location of virtual altimetry stations and the two water level gauge stations in Uganda.

(Mayer-Gürr et al., 2014) to estimate TWS changes (see also Khaki et al., 2017b,c). Lower spherical harmonic degrees components are replaced with more accurate estimates of Swenson et al. (2008) (degree 1 coefficients) and Cheng and Tapley (2004) (Degree 2 and order 0 coefficients). The L2 gravity fields are then converted into $1^{\circ} \times 1^{\circ}$ TWS fields, see (Wahr et al., 1998). Colored/correlated noises in the products are reduced using the Kernel Fourier Integration (KeFIn) filter proposed by Khaki et al. (2018c), which also accounts for signal attenuations and leakage effects caused by smoothing. The KeFIn filter works through a two-step post-processing algorithm. The first step mitigates the measurement noise and the aliasing of unmodelled high-frequency mass variations, while the second step contains an efficient kernel to decrease the leakage errors. Details of this filter can be found in Khaki et al. (2018c).

\subsection{Precipitation, Evaporation, and Discharge}

Precipitation datasets from the Tropical Rainfall Measuring Mission Project (TRMM;3B43 version 7) products (TRMM, 2011), Global Precipitation Climatology Centre (GPCC; Schneider et al., 2008), and CPC unified gauge dataset (Chen et al., 2002) covering the period from 1998 to 2016 at monthly $1^{\circ} \times 1^{\circ}$ spatial resolution are employed.

Evaporation datasets are acquired from MODIS Global Evapotranspiration Project (MOD16; 
Mu et al., 2007), Global Land Evaporation Amsterdam Model (GLEAM; Miralles et al., 2011), and ERA-interim (Simmons et al., 2007) for the same temporal period. These evaporation products are then converted to monthly $1^{\circ} \times 1^{\circ}$ spatial resolution similar to those of precipitation.

Water discharge time series are obtained from (i) the Jinja and Entebbe stations in Uganda, and (ii), from different sources including the Global Runoff Data Centre (GRDC; http://www.bafg.de/), a report produced by Power Planning Associates (PPA, 2007), and River Watch project (http://floodobservatory.colorado.edu/). Similar to precipitation and evaporation datasets, all these discharge products are resampled to monthly average height variations. Figure 1 shows the locations of discharge stations.

\subsection{Satellite Radar Altimetry}

TOPEX/Poseidon (T/P), Jason-1, and Jason-2 data ( 9.915 day temporal resolution) of the Sensor Geographic Data Records (SGDR), which contains 20-Hz waveform data as well as ENVISAT 18-Hz SGDR product (35-day temporal resolution) from RA-2/MWR are used. This includes 360 cycles of T/P covering 1992-2002, 260 cycles of Jason-1 from 2002 to 2008, 277 cycles of Jason-2 covering 2008 to 2016, and 112 cycles of ENVISAT. T/P and Jason-1 data are both derived from the Physical Oceanography Distributed Active Archive Center (PO.DAAC), Jason-2 data is provided by AVISO, and ENVISAT data is obtained from European Space Agency (ESA). Before using these datasets geophysical corrections that include solid earth tide, pole tide, and dry tropospheric (Birkett, 1995) are applied. The data sets are then converted to a monthly scale and used to build virtual time series over different points (see Figure 1) located on the satellite ground tracks over Lake Victoria. At each virtual point, several points belonging to the same satellite cycle are considered, and the median value of the retracked altimetry-based water levels computed to address the hooking effects (Frappart et al., 2006). This effect is derived from off-nadir measurements when a satellite locks over a water body before or after passing above it (Seyler et al., 2008; Boergens et al., 2016). A summary of the datasets used in the present study is presented in Table 1. 
Table 1: A summary of the datasets used in this study.

\begin{tabular}{|c|c|c|c|}
\hline Product & Platform & Reference & Source \\
\hline $\begin{array}{l}\text { Terrestrial water stor- } \\
\text { age (TWS) }\end{array}$ & GRACE & Mayer-Gürr et al. (2014) & $\begin{array}{l}\text { Satellite remote } \\
\text { sensing }\end{array}$ \\
\hline Precipitation & $\begin{array}{l}\text { TRMM- } \\
3 \mathrm{~B} 43\end{array}$ & TRMM (2011) & $\begin{array}{l}\text { Satellite remote } \\
\text { sensing }\end{array}$ \\
\hline Precipitation & GPCC & Schneider et al. (2008) & $\begin{array}{l}\text { Based on in-situ } \\
\text { data }\end{array}$ \\
\hline Precipitation & $\mathrm{CPC}$ & Chen et al. (2002) & Gauge-based \\
\hline Evapotranspiration & MOD16 & Mu et al. (2007) & $\begin{array}{l}\text { Satellite remote } \\
\text { sensing }\end{array}$ \\
\hline Evapotranspiration & GLEAM & Miralles et al. (2011) & $\begin{array}{l}\text { Model and satel- } \\
\text { lite remote sens- } \\
\text { ing }\end{array}$ \\
\hline Evapotranspiration & $\begin{array}{l}\text { ERA- } \\
\text { interim }\end{array}$ & Simmons et al. (2007) & $\begin{array}{l}\text { Reanalysis } \\
\text { dataset }\end{array}$ \\
\hline Altimetry water height & $\begin{array}{l}\mathrm{T} / \mathrm{P} \\
\text { Jason-1 }\end{array}$ & http://podaac.jpl.nasa.gov & $\begin{array}{l}\text { Satellite } \\
\text { sensing }\end{array}$ \\
\hline Altimetry water height & Jason-2 & http://avisoftp.cnes.fr/ & $\begin{array}{l}\text { Satellite remote } \\
\text { sensing }\end{array}$ \\
\hline Water discharge & $\begin{array}{l}\text { Jinja } \\
\text { and } \\
\text { Entebbe } \\
\text { stations }\end{array}$ & $\begin{array}{l}\text { Ministry of Energy \& Mineral De- } \\
\text { velopment Kampala (Uganda) }\end{array}$ & In-situ \\
\hline Water discharge & GRDC & $\begin{array}{l}\text { http://www.bafg.de/GRDC/EN/ } \\
\text { Home/homepage_node.html }\end{array}$ & In-situ \\
\hline Water discharge & PPA & $\begin{array}{l}\text { Power Planning Associates (PPA, } \\
\text { 2007) }\end{array}$ & In-situ \\
\hline Water discharge & $\begin{array}{l}\text { River } \\
\text { Watch }\end{array}$ & $\begin{array}{l}\text { http://floodobservatory. } \\
\text { colorado.edu/ }\end{array}$ & In-situ \\
\hline
\end{tabular}

\section{Method}

\subsection{Data integration}

A two-step data combination approach proposed by Aires (2014) is applied, where first, a Simple Weighting (SW) approach is employed to merge different precipitation and evaporation data sets leading to new merged (precipitation and evaporation) products. These merged precipitation and evaporation products together with those of GRACE TWS and discharge are passed through a Postprocessing Filtering (PF) procedure to generate improved precipitation $(\mathbf{p})$, evaporation $(\mathbf{e})$, water storage changes $(\Delta \mathbf{s})$, and discharge $(\mathbf{q})$ that accounts for water budget closure. Compared to other techniques, the SW approach has been shown to 
perform better e.g., Aires (2014). During the SW step, the filter assigns a weight to each water component (e.g., for each precipitation and evaporation product). The PF step that is based on the water balance equation then checks the water budget closure (Eqs. 1 and 2) using a Kalman-based scheme.

$$
\begin{gathered}
\mathbf{p}-\Delta \mathbf{s}-\mathbf{e}-\mathbf{q}=\mathbf{0}, \\
\mathbf{X}^{\mathbf{T}} \cdot \mathbf{G}=\mathbf{0},
\end{gathered}
$$

with $\mathbf{X}^{\mathbf{T}}=(\mathbf{p}, \boldsymbol{\Delta} \mathbf{s}, \mathbf{e}, \mathbf{q})$ ( $T$ indicates matrix transpose), calculated from the first step (SW), and $\mathbf{G}^{\mathbf{T}}=(\mathbf{1}, \mathbf{- 1}, \mathbf{- 1}, \mathbf{- 1})$. A Kalman-like solution (following Pan and Wood, 2006) is then applied by,

$$
\begin{gathered}
\mathbf{X}_{\mathbf{a}}=\mathbf{K} \cdot \mathbf{X}, \\
\mathbf{K}=\left(\mathbf{I}-\mathbf{B G}\left(\mathbf{G}^{\mathbf{T}} \mathbf{B G}\right)^{-\mathbf{1}} \mathbf{G}^{\mathbf{T}}\right),
\end{gathered}
$$

where $\mathbf{I}$ is identity matrix and $\mathbf{B}$ is the error covariance matrix of $\mathbf{X}$ from SW. The application of PF guarantees that the estimated flux nets in $\mathbf{X}_{\mathbf{a}}$ are balanced (see details in Aires, 2014; Munier et al., 2015).

\subsection{Extrema Retracking (ExtR)}

Satellite radar altimetry, originally designed to monitor sea level changes, nowadays are also used to monitor inland water bodies (see, e.g., Birkett, 1995) and rivers (see e.g., Birkett et al., 2002; Berry et al., 2005; Tseng et al., 2013). Nevertheless, the waveform retracking, which refers to the re-analysis of the waveforms, a time-series of returned power in the satellite antenna (Davis et al., 1995; Gomez-Enri et al., 2009), is required to improve the accuracy of measured ranges (or sea surface height; SSH) over inland waters (Brown, 1977). Here, to retrack satellite radar altimetry data, a developed Extrema Retracking (ExtR) algorithm proposed by Khaki et al. (2014) is applied to generate refined virtual lake level heights that are used in the water storage analysis step. It should be pointed out that this water analysis step uses improved water storage changes obtained from the SW and PF steps (see Figure 3). Our motivation for selecting the ExtR algorithm is due to its processing speed and its promising results that were obtained over the Caspian Sea when compared to the Off Center of Gravity (OCOG, Wingham et al., 1986), the NASA $\beta$-Parameter Retracking (Martin et al., 1983), and 
Threshold Retracking (Davis, 1997). The ExtR is applied to the altimetry-derived waveforms to retrack datasets, which is necessary for inland applications of satellite radar altimetry. The Khaki et al. (2014) algorithm includes three steps; (i) applying a moving average filter to reduce the random noise of the waveforms, (ii) identifying extremum points of the filtered waveforms, and (iii), exploring the leading edges among all detected extremum points. Range corrections are applied using the offset between the position of the leading edges and their on-board values.

Two gauge stations around Lake Victoria (see Figure 1) located at Jinja (1992-1995) and Entebbe (1992-2009) from the Ministry of Energy \& Mineral Development Kampala (Uganda), Old Aswan (1996-2009), Esna Barrage (1996-2009), and Naga Hammadi Barrage (1996-2007), and Assiut Barrage (1996-2009) from Ismail and Samuel (2011), and Nubaria (1997-2007) from Samuel (2014) are used to examine the performance of the ExtR filter. Retracked time series of two closest virtual stations to the in-situ stations are compared to the in-situ water level measurements. The average bias and standard deviation (STD) of average errors for both stations are presented in Figure 2. Significant decreases in both bias and STD are found after applying the filtering process (cf. Figure 2). The figure shows the capability of the ExtR filter for reducing errors and justifying its usage in this study.

\subsubsection{Climate Variability Impacts}

In order to investigate the impacts of climate variability/change on LV's water storage changes, correlation analysis is used. Hereafter, reported correlation values between any two variables are calculated as the average of correlation between their time series at all grid points. Furthermore, principal component analysis (PCA; Lorenz, 1956; Preisendorfer, 1988) is applied on the improved precipitation, evaporation, and water storage time series (after filtering in Section Section 3.1) to better analyze the spatio-temporal changes of water storages and climatic indicators. This is done to examine the climate patterns within the LV area and to investigate their connections to water storage changes. Since precipitation and evaporation are the major effective parameters on water storage recharge, the process helps to study the role of climate variability on water storage variations. A schematic illustration of the applied processing steps in this study, i.e., data integration procedure, retracking, and climatic impacts exploration, is provided in Figure 3. 

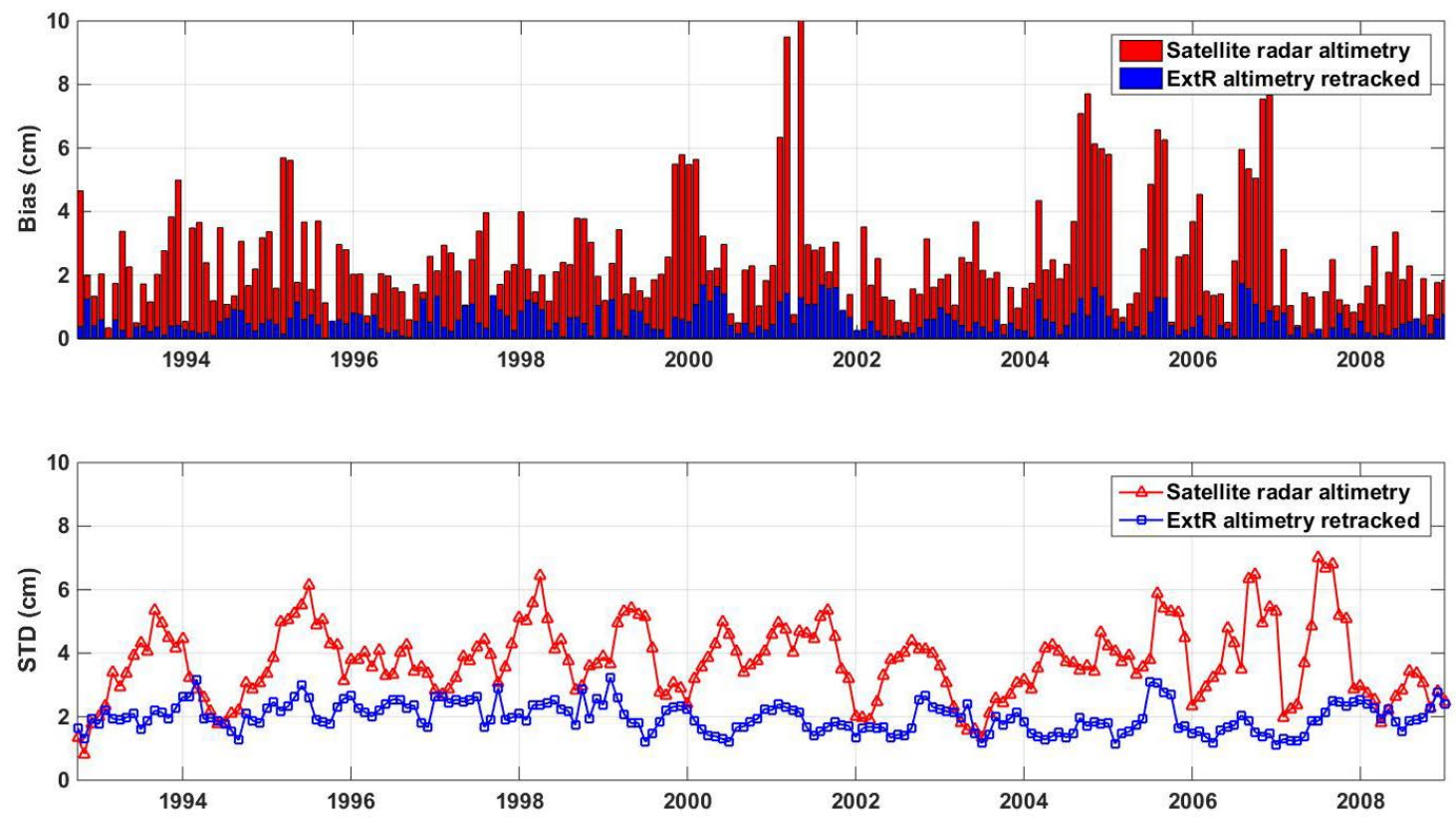

Figure 2: Average bias and STD of the error time series, i.e., the difference between altimetry data and in-situ measurements. These graphs are generated using retracked time series of two closest virtual stations to the in-situ stations and corresponding in-situ water level measurements. The figure shows that the ExtR filter (blue graphs) reduces retracked errors and thus improves the satellite altimetry products employed in this study.

\section{Results and Discussion}

First, we present the two-step $(\mathrm{SW}+\mathrm{PF})$ filtering results and the impact of the process on individual data type, as well as on the balance between them. Afterwards, spatio-temporal variations of precipitation and TWS and their interactions as major components of water fluxes are investigated.

\subsection{Coherent filtered products}

To demonstrate the usefulness of the SW+PF for filtering remotely sensed datasets for Lake Victoria, correlations between the original and filtered time series of each water cycle component and other filtered components are calculated in order to assess how the filtering process increases the agreement between different water cycle components. Table 2 shows the average improvements in the correlations between every two products, i.e., how each estimated water flux is correlated with other flux observations. Note that this is done to assess the effect of the applied method to produce a more coherent data, which does not necessarily lead to a higher accuracy. Correlation values between the original and filtered water fluxes, e.g., original 


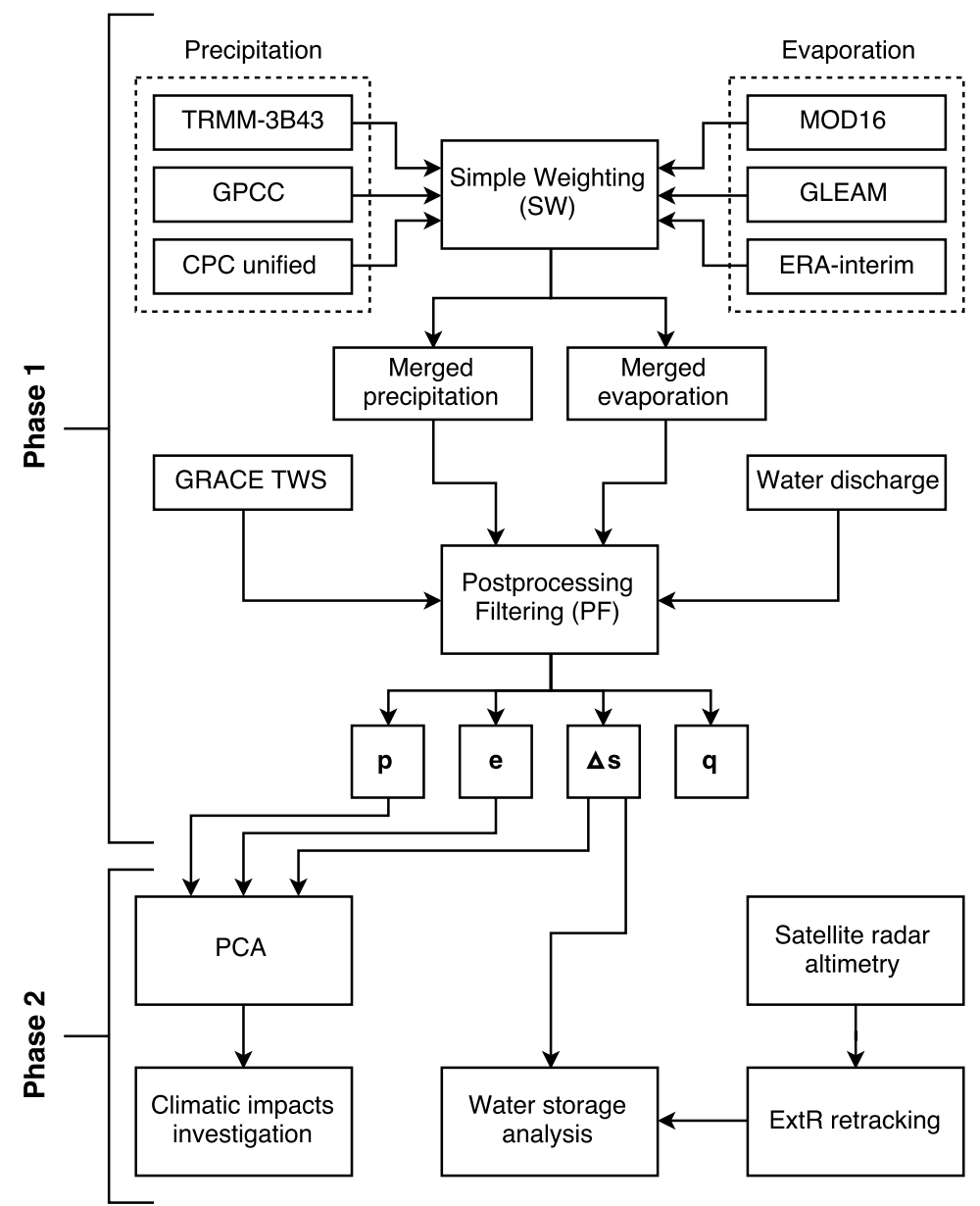

Figure 3: A schematic illustration of the applied methodology. The algorithm operates in two steps. First, the SW approach is employed to merge the precipitation and evaporation data sets. The merged products together with those of GRACE TWS and discharge are then subjected to the PF filter in the second step to produce improved water budget parameters.

and filtered $\mathbf{p}$ and all data products of $\mathbf{e}, \Delta \mathbf{s}$, and $\mathbf{q}$ are calculated to allow for estimation of achieved improvement in the filtered data. It is evident that in all the cases, improvements are achieved between any two filtered datasets. For example, between the original GPCC products and filtered precipitation time series, the later is $13.48 \%$ more correlated to filtered water storage changes. It can also be seen that the obtained improvements are different for various products. In general, for precipitation, higher increase in correlation is achieved from GPCC while less improvements are found in CPC, which is gauge-based. A similar correlation improvement can also be seen for evaporation, where different products (e.g., MOD16, GLEAM, and ERA-interim) receive various weights in the process, which correspondingly lead to various 
levels of improvements. Based on the results in Table 2, it can be concluded that the filtered $\mathbf{p}, \mathbf{e}, \Delta \mathbf{s}$, and $\mathbf{q}$ products are largely in agreements.

Table 2: Average correlation improvements (\%) between different variables. Note that $\mathbf{p}, \mathbf{e}, \Delta \mathbf{s}$, and $\mathbf{q}$ refer to the filtered water cycle components of precipitation, evaporation, water storage changes, and discharge. Improvements in the correlation $(r)$ values are calculated as $\left[\left(r_{\text {filtered results }}-r_{\text {original data }}\right) / r_{\text {original data }}\right] \times$ $100(\%)$.

\begin{tabular}{lcccc}
\hline & $\mathbf{p}$ & $\mathbf{e}$ & $\Delta \mathbf{s}$ & $\mathbf{q}$ \\
\hline $\mathbf{p}$ (compared to TRMM-3B43) & 0 & 8.51 & 12.93 & 9.81 \\
$\mathbf{p}$ (compared to GPCC) & 0 & 13.48 & 16.75 & 11.32 \\
$\mathbf{p}$ (compared to CPC) & 0 & 2.73 & 6.14 & 5.73 \\
$\mathbf{e}$ (compared to MOD16) & 9.50 & 0 & 11.65 & 6.69 \\
$\mathbf{e}$ (compared to GLEAM) & 8.36 & 0 & 8.01 & 7.17 \\
$\mathbf{e}$ (compared to ERA-interim) & 18.18 & 0 & 14.44 & 9.20 \\
$\Delta \mathbf{~ s ~ ( c o m p a r e d ~ t o ~ G R A C E ~ T W S ) ~}$ & 16.56 & 12.94 & 0 & 15.58 \\
$\mathbf{q}$ (compared to initial discharge) & 11.11 & 07.08 & 9.52 & 0 \\
\hline
\end{tabular}

In addition to correlation improvements above, based on water balance equation, the $\mathrm{SW}+\mathrm{PF}$ filtering algorithms also corrects for imbalance between the water cycle components. The postprocessed water fluxes from the application of the $\mathrm{SW}+\mathrm{PF}$ filter is displayed in Figure 4. Four filtered water budget components of precipitation, evaporation, TWS changes and discharge show different performance in the water balance equation (Figure 4a). Precipitation and water storage changes are seen to have the largest contributions, i.e., 37\% and 35\%, respectively. Evaporation shows $19 \%$ contribution while runoff depicts the least contribution of $9 \%$. The large value of the evaporation contribution, corroborated also by the findings of (Mohamed et al., 2005), indicates that a big part of precipitation over the lake area cannot recharge the outflow river (e.g., White Nile).

Figure $4 \mathrm{~b}$ illustrates the imbalance error before and after using the $\mathrm{SW}+\mathrm{PF}$ filtering, showcasing the capability of the filters to reduce the imbalance between water cycle components in order to provide a more coherent data sets. This is also evident from the correlations between altimetry level variations and the fluxes before and after filtering. The average correlation improvement of $12 \%$ is obtained between lake height variations and all the four components after applying the $\mathrm{SW}+\mathrm{PF}$ filtering algorithm. In spite of this improvement after applying the filter, the imbalance between component can still be seen. This can be attributed to various factors such as observation errors, the contribution of groundwater in- and out-flows and its interaction with surface storage, and also the impact of extreme climatic impacts, which can be underestimated in reanalysis and remote sensing observations contrary to the in-situ discharge 

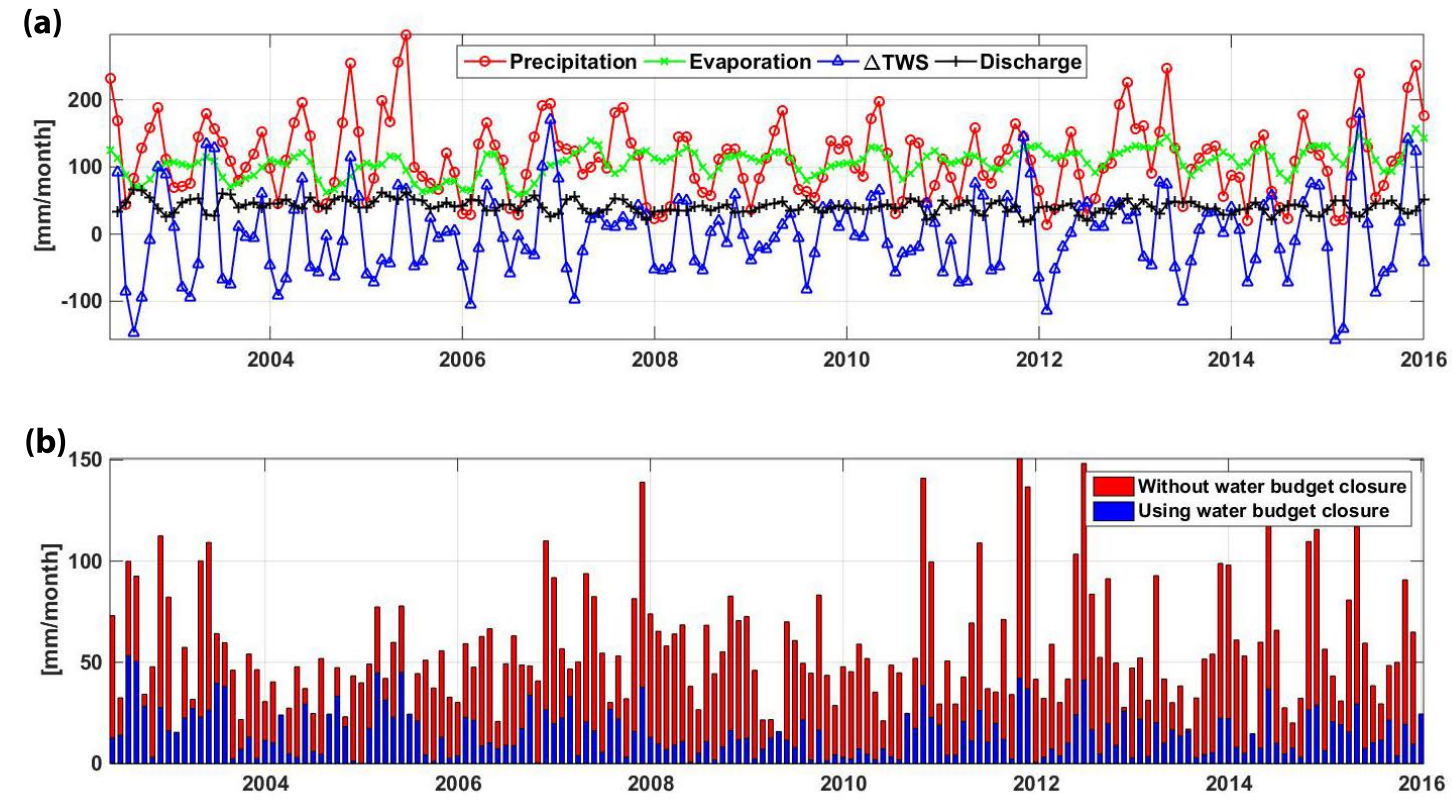

Figure 4: Water components variations after filtering using SW+PF (a). The imbalance errors before and after applying the filter are shown in (b).

measurements. In what follows, these improved (merged and filtered) products are used to analyze trends in Lake Victoria's water in the face of climate variation/change impacts.

\subsection{Climatic variation/change impacts}

To investigate the impacts of climatic variation/change on the Lake Victoria water storage, first a comparison of the average variations of precipitation, evaporation, and water storage changes within the lake is made. Figure 5 shows the average time series of three data types from various sources including filtered and unfiltered products over the entire LVB. Note that 6 months running mean is applied to filter out high-frequency variations leading to better representations of variations and trends. As can be clearly seen, the filtered results are in a large agreement (0.91 average correlation between each two time series) compared to the two other samples from original (unfiltered) datasets, thus indicating the capability of the applied filtering method for achieving coherent data. Water storage changes largely follow the precipitation and evaporation patterns in Figure 5 top panel. This shows that climate is the most effective factor in the lake's water storage changes. As expected, there is also a large agreement between precipitation and water discharge, especially after the filtering process. This agreement is better discussed by comparing Figures 5 top and bottom panels, in which 
the original datasets are plotted. In addition to the time series' patterns, it can also be seen that the filtering approach affects the time series' magnitudes. For example, the magnitude of precipitation after the filtering is different from the original data in Figure 5 middle and bottom panels. From Figure 5, several significant positive and negative variations can be seen. Increases in rainfall in 2005, 2007, 2013, and 2016 cause similar rise in water storages. On the contrary, declines are observed in all time series during 2006 and 2014. Furthermore, it can be seen in Figure 5 (bottom and middle panels) that a larger discrepancy exists between precipitation and two other flux observations. Due to the large evaporation rate over Lake Victoria, this larger interaction with water storage is expected. Such a connection, which can be absent on other water bodies depend on their characteristics, and can affect the water flux covariance matrix and violate the assumption of independence observation made on water budget closure. Here, however, the impact of this partial dependency between water storage and evaporation is neglected mainly due to the fact that no information is available in this regard.

To better understand water storage changes and the associated climatic impacts over the lake, PCA method is employed to the merged filtered precipitation, evaporation, and water storage changes. Figure 6 shows the spatial variations of these datasets within LVB corresponding to the first three empirical orthogonal functions (EOFs) of the PCA analysis. The spatial variability of water storage changes matches those of precipitation and evaporation in most of the areas proving that they are the dominant indicator of the impacts of climate indicators on LVB water storage. It can be seen that the main rainfall pattern exists in the central (EOF1) parts of the lake corresponding to a similar pattern in evaporation and water storage. The main water storage patterns, as expected, are observed in the central parts of the Lake Victoria (EOF1) as a result of recharge from rainfall in this area. EOF2 shows considerable positive signals in the western parts. This could be attributed to the contribution of Kagera river to the lake's water changes. Kagera river, which originates from Burundi, is the largest inflow into Lake Victoria. To a lesser degree, larger rainfall, evaporation and water storage can be observed in the eastern parts (EOF3) of the lake resulting from the effect of the south east monsoon trade winds (e.g., Awange et al., 2008, 2013a) and possible recharge from the Grummeti, Simivu, and Mara rivers. Major rainfall spatial variabilities in the central (EOF1) and western (EOF2) parts corroborate the findings in (Awange et al., 2008, 2013a), which shows that these parts are responsible for most of the rainfalls occurring over Lake Victoria and its water recharge thereby resulting in a larger evaporation and water storage changes. 

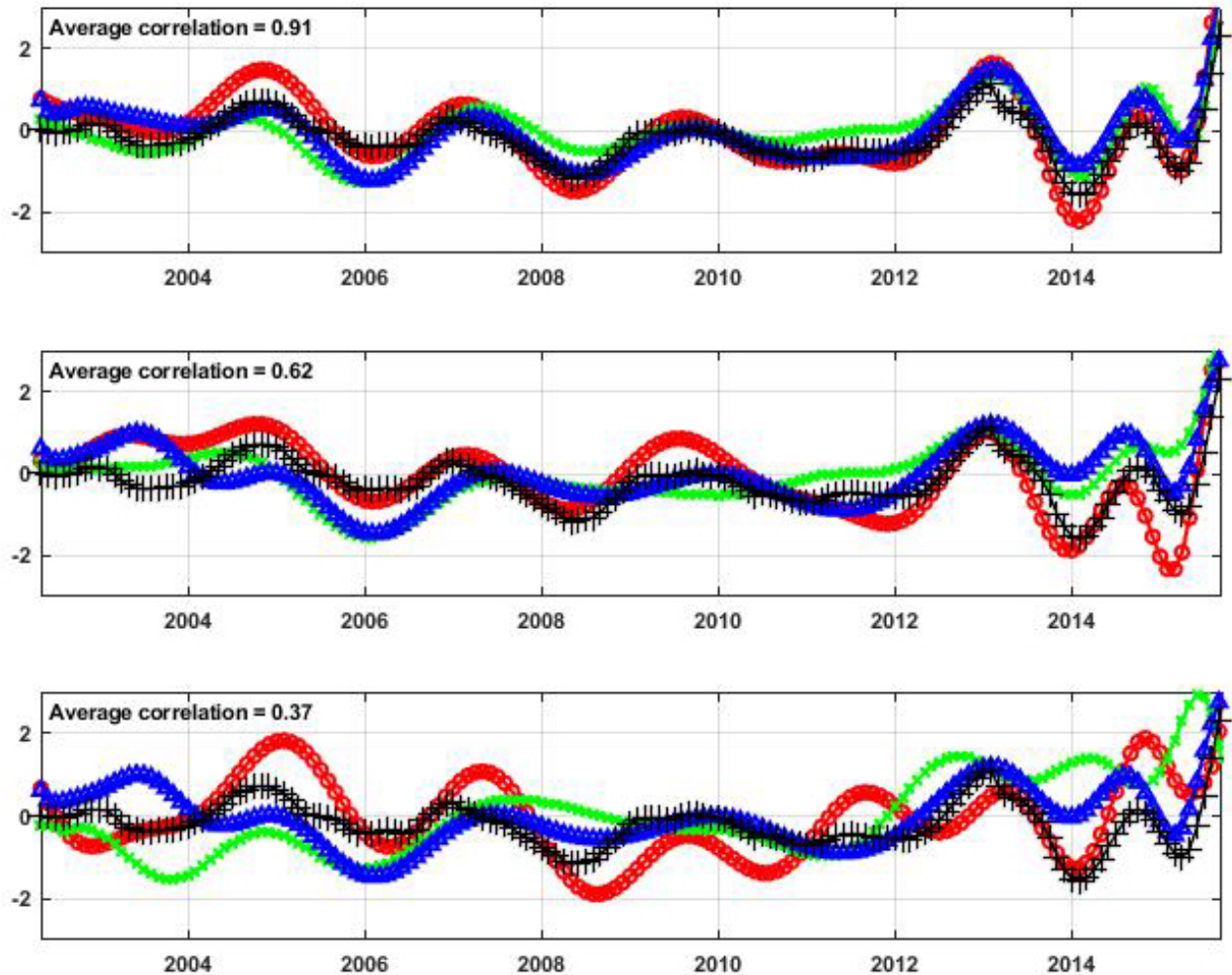

Figure 5: Average (6 months running mean) precipitation (red), evaporation (green), water discharge (black), and water storage variations (blue) from different sources including filtered products (top), original TRMM, MOD16, and GRACE (middle), and original GPCC, GLEAM, and GRACE (bottom). Note that normalized values (based on the time series STD) are represented for a better visual comparison. Note that precipitation and evaporation data in the middle and bottom panels are selected randomly to show how different they can act.

Figure 7 shows the corresponding first three principal components (PCs) time series. The dominant seasonal (PC1) and annual (PC2) rainfall patterns can be seen, which are in agreements with those of evaporation and water storage changes. Some significant anomalies can also be observed in precipitation, e.g., the large negative anomalies observed in 2006 (PC2) and 2014 (PC1 and PC3), and significant positive variations observed, e.g., in 2005 and 2007 (PC1, PC2, and PC3), 2010 (PC1), 2013 (PC1 and PC2), and 2016 (PC1). These variations can also be seen in evaporation and water storage changes time series, especially the rises in 2005, 2007, and 2013. The 2007 ENSO rainfall effect (e.g., Omondi et al., 2013; Awange et al., 2014) is evident in PC1 for all three datasets. A negative trend is found between 2003 and 2005 for water storage time series similar to those of evaporation (PC1). This could be attributed to excessive water usages reported in the works of Awange et al. (2008) and Swenson and Wahr (2009) while such a negative trend is absent in rainfall time series. Large rainfalls, generally 

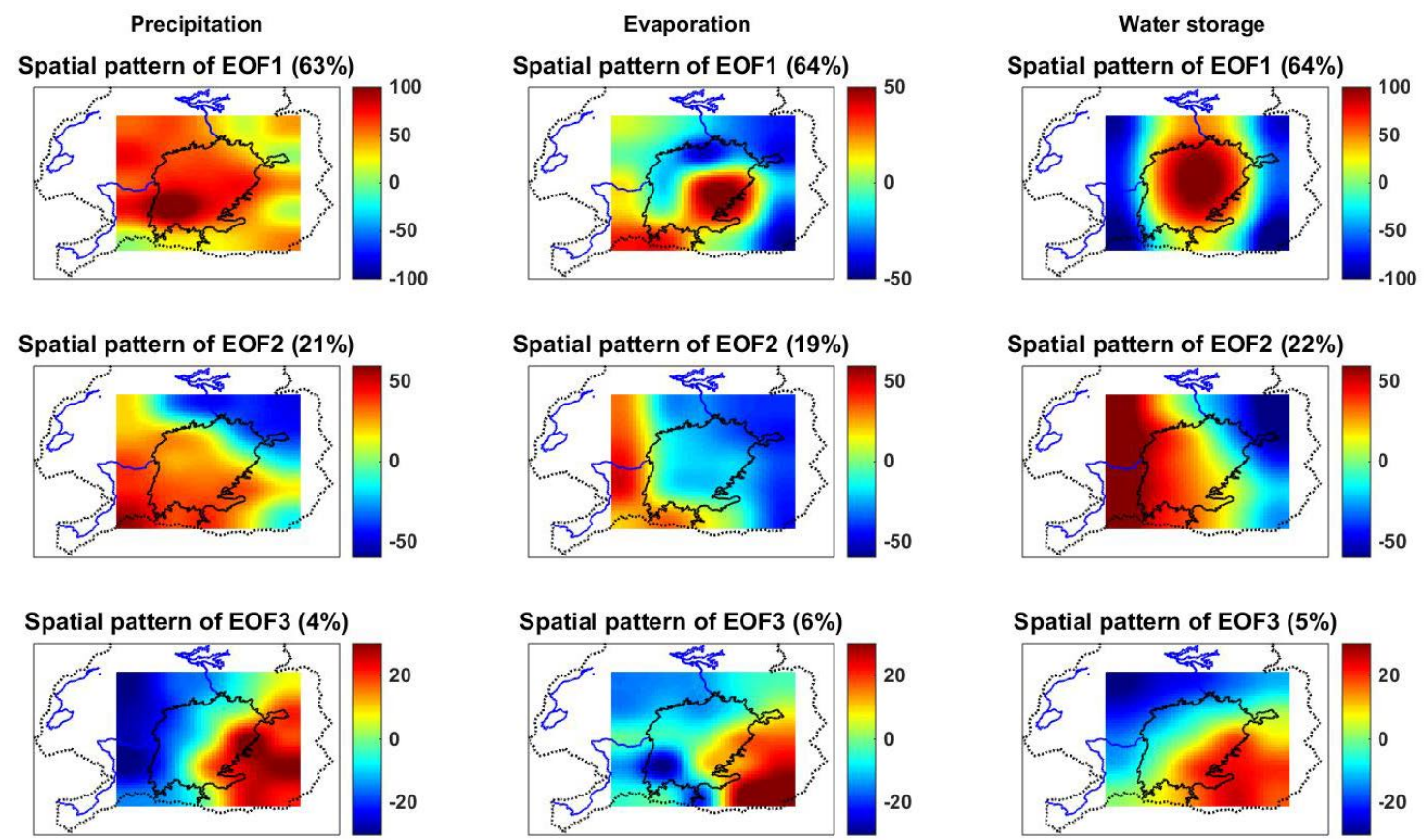

Figure 6: Spatial variations of precipitation, evaporation, and water storage changes from the first three empirical orthogonal functions (EOFs) of PCA (units are mm). The central (EOF1), western (EOF2) and the eastern parts (EOF3) show large amount of variations.

after 2013 result in positive water storage and evaporation trends. A decrease in rainfall is captured after 2011 due to the drought that affected the region (see, e.g., Awange et al., 2013b), which causes a decline in water storage variations. These similar patterns suggest a close tie between water storage variabilities and climatic impacts.

These similar patterns in climatic indicators and water storage changes, in terms of spatial (cf. Figure 6) and temporal (cf. Figure 7) variabilities, suggest a close tie between water storage variabilities and climatic impacts. This can also be seen in Figures 8 and 9, which show annual spatial variations and trends, and temporal variations of precipitation and water storage over the area, respectively.

It can be seen in Figure 8 that the major variations exist in the south-eastern parts, for both precipitation and water storage. A similar pattern is found for trends (right panels in Figure 8). This means that precipitation plays the main role in the lake's water storage variations as already reported in other studies (e.g., Nicholson et al., 2003). One can see the same effects from the time series in Figure 9, where the agreement between rainfall changes (top panel) and the lake's water storage changes (bottom panel) emphasizes the impact of rainfall on Lake Victoria. 

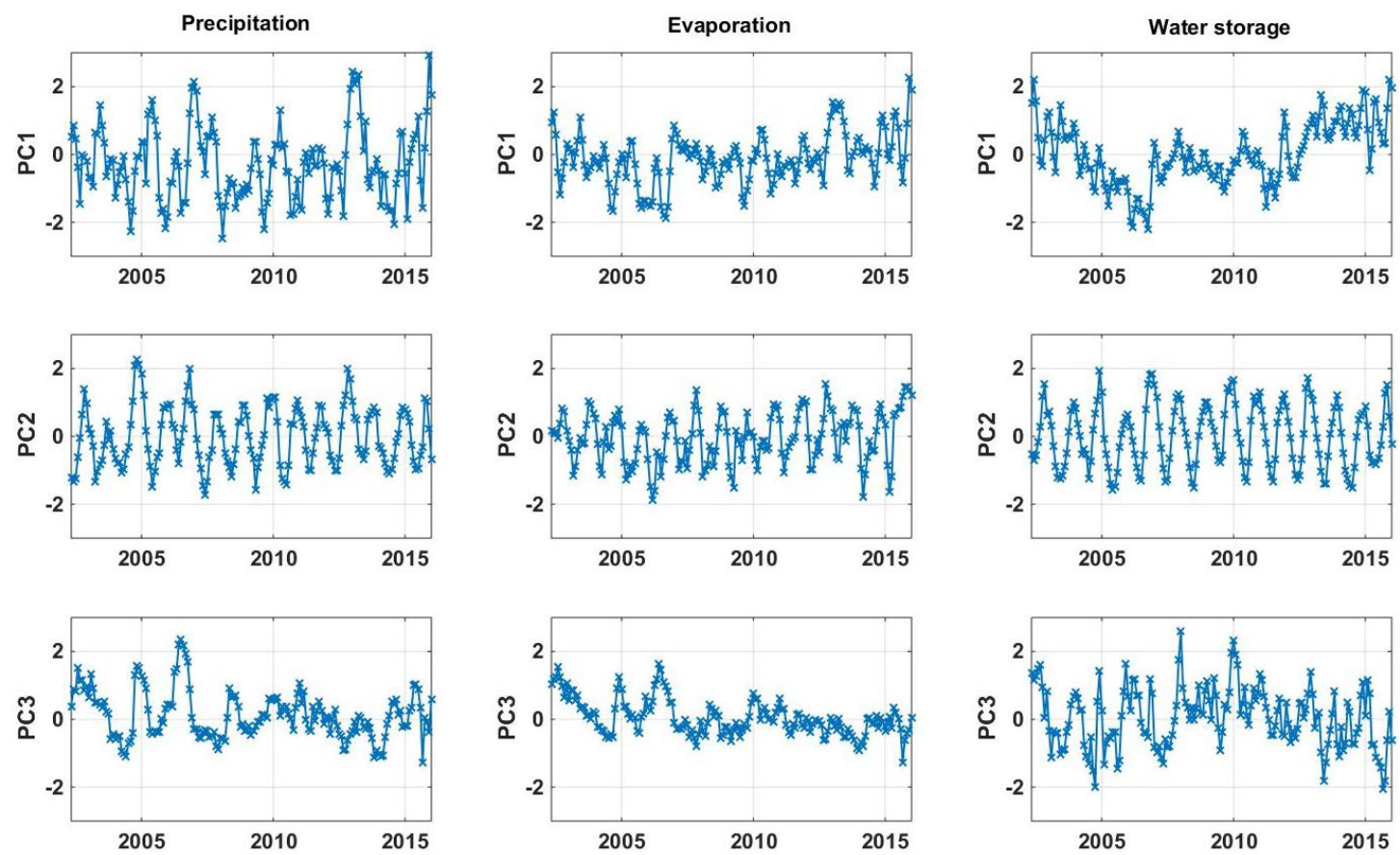

Figure 7: The first six principal components (PCs) time series of precipitation, evaporation, and water storage changes from PCA. While the seasonal pattern (PC1) and annual (PC2) are dominant, several considerable positive and negative variations (e.g., in 2005 and 2007 (PC1 and PC2), and 2014 (PC3)) can also be seen in PCs.

Above-average rainfalls during 2007 El'niño significantly affected water storage variations corresponding to the large anomalies. Nevertheless, as previously mentioned, the large contribution of evaporation does not allow water storage changes to perfectly match precipitation time series variations, e.g., in 2012 and after 2014. The impact of climate variability influences the balance between precipitation and evaporation and subsequently impacts the lake's depth and arguably its areal extent and correspondingly water storage changes (e.g., Owor et al., 2011). Another effective factor on water storage changes is groundwater within the area, which has been under larger influences by the growing population in recent years. Nevertheless, there is not much strong evidence of interaction between groundwater and surface water mainly due to the lack of ground-based groundwater measurements.

To better study Lake Victoria's stored water changes, analyzing its surface water variations is essential. To this end, altimetry-derived surface water changes are plotted in Figure 10 and compared with TWS changes from GRACE. The water level height variations in Figure 10 depicts a large agreement to water storage variations. A large negative trend is found between 

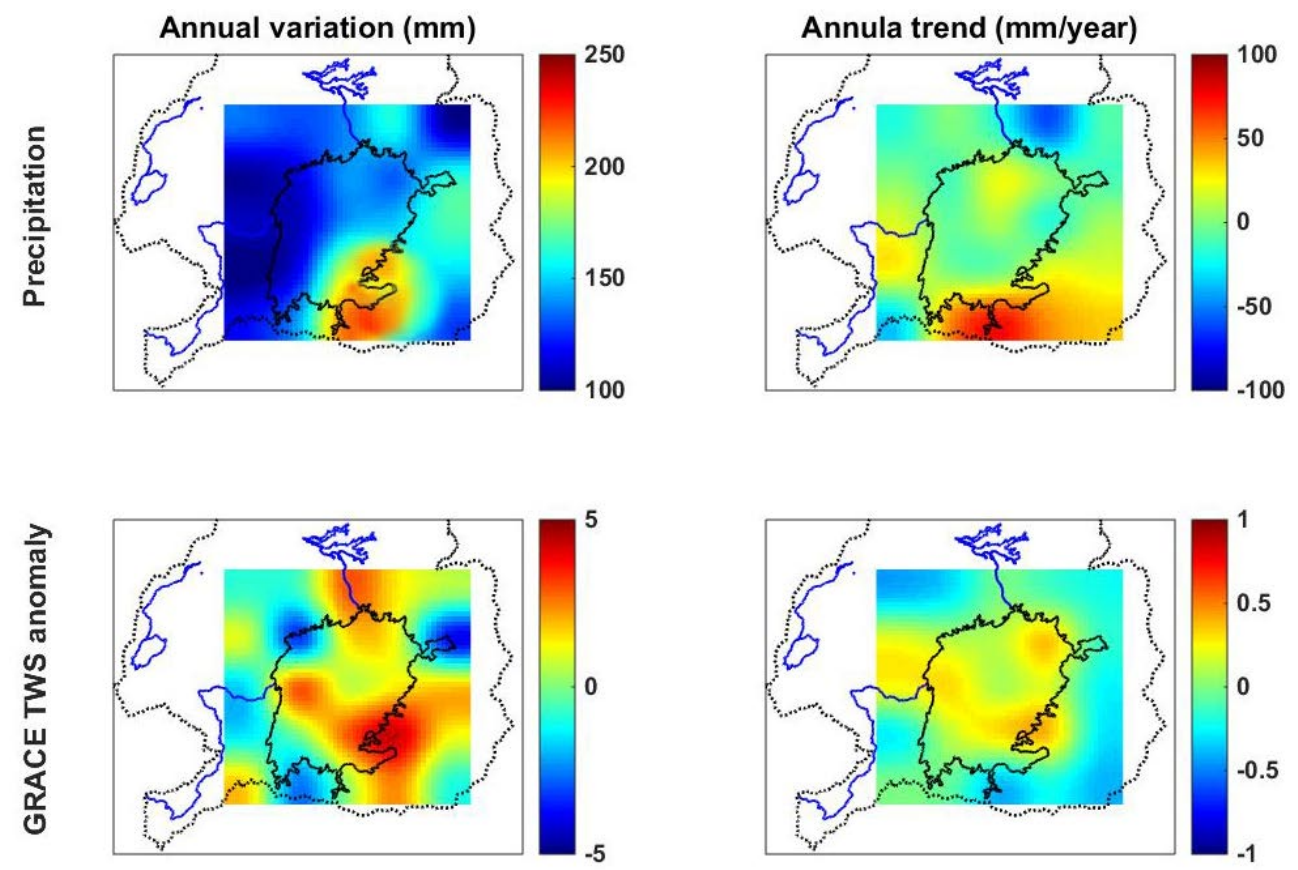

Figure 8: Average annual variations and trends of precipitation and the filtered water storage time series at each grid point.
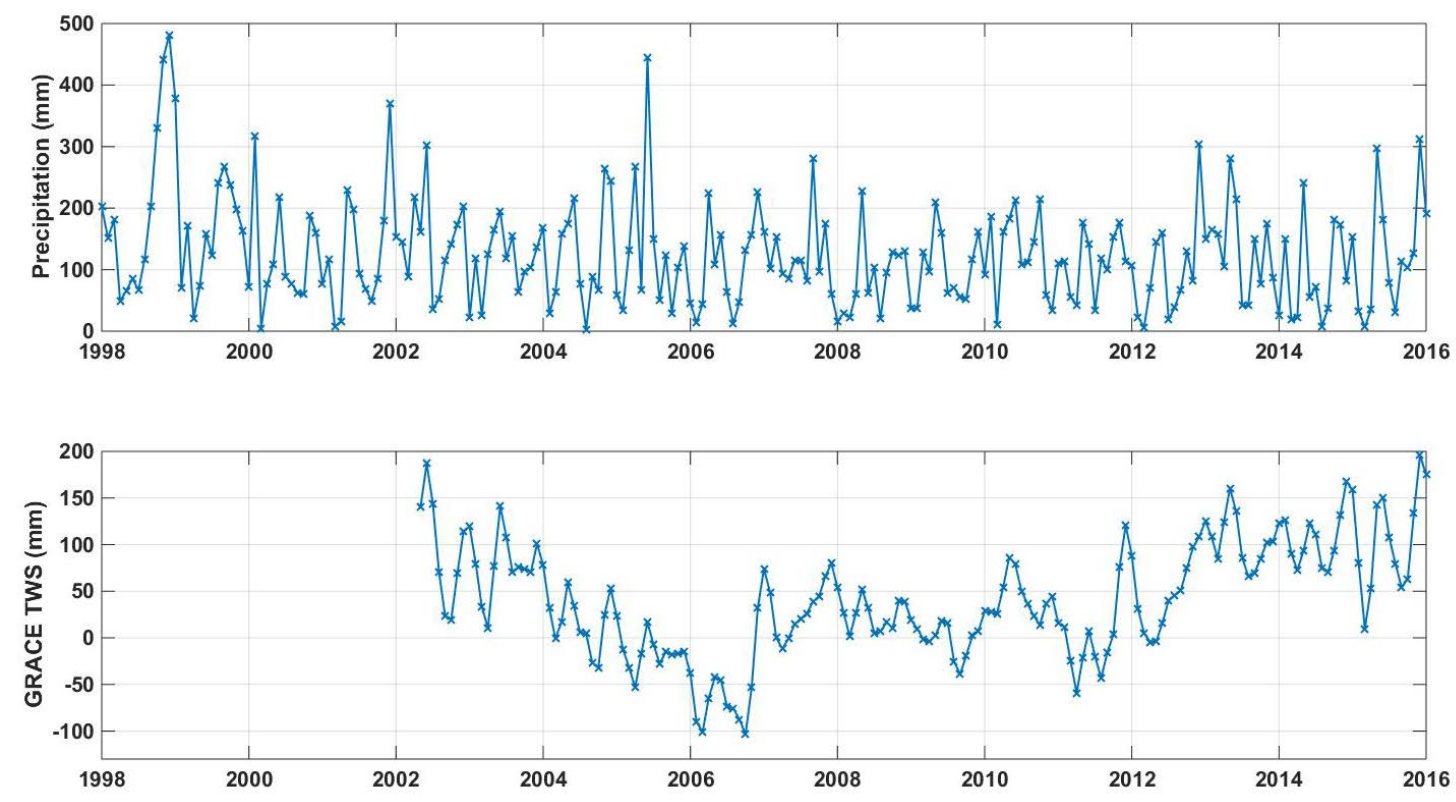

Figure 9: Spatially averaged time series of precipitation and the filtered water storage changes within the Lake Victoria. 
1998 and 2006 before a remarkable positive anomaly due to the effects of 2007 ENSO. The lake's water level variation also closely follows rainfall pattern. Larger rainfalls before 1998 result in a water level increase in the same period, which ends with a remarkable positive anomaly in 1998 due to an excessive ENSO rainfall in 1997. Decreases in water level are also observed for the period of 2002 to 2004 and after 2007 similar to water storage variations. This large agreement between GRACE-derived TWS variations and altimetry-derived surface water changes suggests that the impact of groundwater and its interaction with surface storage is minimal. This justifies the common assumption that has been made by a number of previous studies (see,e.g., Kite, 1982; Sene and Plintson, 1994; Nicholson and Yin, 2001), in which they ignore the groundwater contribution to the Lake Victoria.

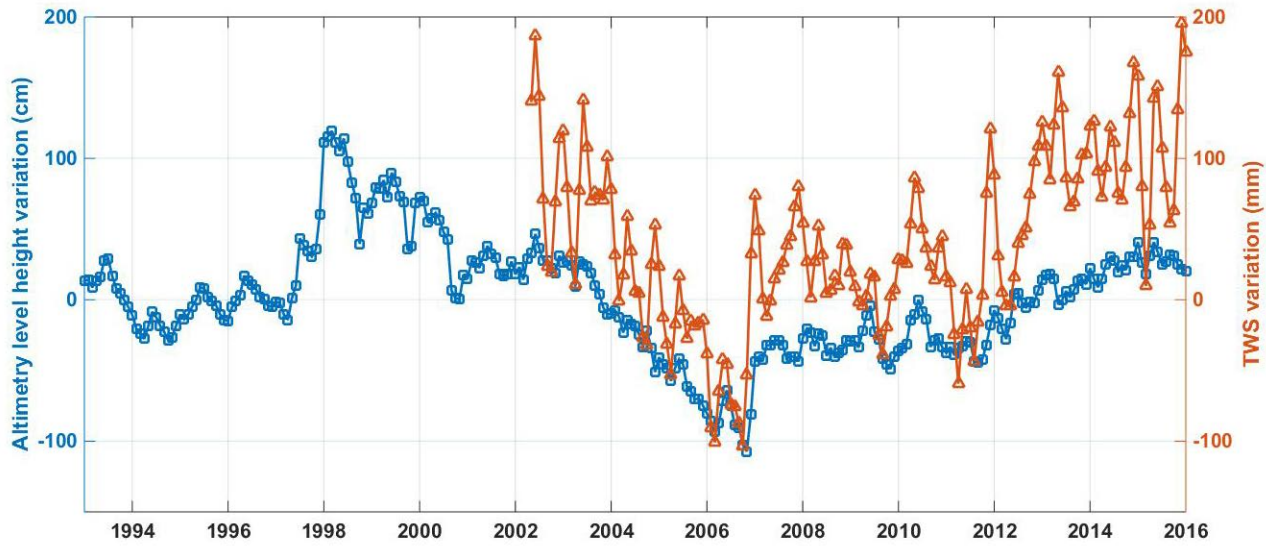

Figure 10: Comparison between average time series of altimetry-derived lake level variation (after applying ExtR retracking) and the filtered water storage variations.

\section{Conclusion}

The present study (i) investigated the capability of the two-step data-driven approach of Simple Weighting (SW) and Postprocessing Filtering (PF) to improve remotely sensed datasets through merging and filtering to obtain four water cycle key components; precipitation, evaporation, discharge, and water storage variations, and (ii), explored the impacts of climate variabilities on water storage changes using the improved datasets in (i). The application of this approach, for the first time for LVB, results in a more efficient analysis of water fluxes that preserve water balance. The filtered water fluxes were largely in agreement compared to the original unfiltered datasets. This shows that SW+PF merging and filtering approach can effec- 
tively reduce imbalances between different observations over a limited scale inland water bodies.

It was also found that there is a remarkably smaller imbalance between the post-processed time series with various rates of contribution for each water component, e.g., $37 \%$ and $35 \%$ for precipitation and water storage changes, respectively, as the largest contributions. The achieved coherent datasets allowed for a better analysis of the lake's water changes. Based on these, major rainfall spatial variabilities were observed in the central and western parts of the lake corresponding to the similar pattern in water storage changes. In addition, various strong anomalies were found in the filtered time series, e.g., in 2006 and 2014 (being negative), and 2005, 2007, and 2010 (being positive). The study showed that the climatic variation/change through the precipitation and evaporation (as indicators) are the main sources of the water storage changes within the lake. Moreover, an average correlation of 0.93 was found between water storage changes and the lake's water level variations, which suggests that the main part of water storage changes within the lake refers to the variation of surface storages. These findings suggest the possible application of the applied algorithm to any inland lake that permits the use of satellite remote sensing, especially GRACE for studying water storage changes.

\section{References}

Aires, F. (2014); Combining datasets of satellite retrieved products. Part I: Methodology and water budget closure. Journal of Hydrometeorology, 15 (4), 1677-1691.

Aman, A. (2014); Egypt seeks to halt Ethiopian dam, Al-Monitor: the Pulse of the Middle East. AlMonitor. Retrieved April 23, 2014, http://www.almonitor.com/pulse/originals/2014/02/egypt-lobby-renaissance-damethiopia.html.

Anyah, R.O., Forootan, E., Awange, J.L., Khaki, M. (2018); Understanding linkages between global climate indices and terrestrial water storage changes over Africa using GRACE products, Science of The Total Environment, Volume 635, Pages 1405-1416, ISSN 0048-9697, https://doi.org/10.1016/j.scitotenv.2018.04.159.

Awange, J.L., Sharifi, M.A., Ogonda, G. et al. (2008); The Falling Lake Victoria Water Level: GRACE, TRIMM and CHAMP Satellite Analysis of the Lake Basin. Water Resour Manage, 22: 775, http://dx.doi.org/10.1007/s11269-007-9191-y. 
Awange, J.L., Anyah, R., Agola, N., Forootan, E., Omondi, P. (2013a); Potential impacts of climate and environmental change on the stored water of Lake Victoria Basin and economic implications, Water Resources Research 49 (12), 8160-8173.

Awange, J.L., Forootan, E., Kusche, J., Kiema, J.B.K., Omondi, P.A.,Heck, B., Fleming, K.,

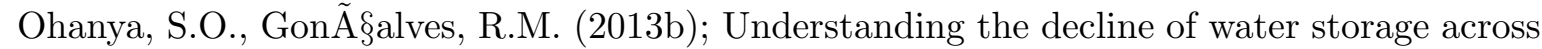
the Ramser-Lake Naivasha using satellite-based methods, Advances in Water Resources, Volume 60, Pages 7-23, ISSN 0309-1708, http://dx.doi.org/10.1016/j.advwatres.2013.07.002.

Awange, J.L., Gebremichael, M., Forootan, E., Wakbulcho, G., Anyah, R., Ferreira, V.G., Alemayehu, T. (2014); Characterization of Ethiopian mega hydrogeological regimes using GRACE, TRMM and GLDAS datasets, Advances in Water Resources, Volume 74, December 2014, Pages 64-78, ISSN 0309-1708, http://dx.doi.org/10.1016/j.advwatres.2014.07.012.

Berry, P.A.M., Garlick, J.D., Freeman, J.A., Mathers, E.L. (2005); Global Inland Water Monitoring from Multi-Mission Altimetery. Geophysical Research Letter 32: L16401, http://dx.doi.org/10.1029/2005GL022814.

Birkett, C.M. (1995); The Contribution of TOPEX/POSEIDON to the Global Monitoring of Climatically Sensitive Lakes. Journal of Geophysical Research 25: 179-25.

Birkett, C., Murtugudde, R., Allan, T. (1999); Indian Ocean climate event brings floods to East Africa's lakes and the Sudd Marsh. GRL, 26(8), pp.1031-1034.

Birkett, C.M., Mertes, L.A.K., Dunne, T., Costa, M.H., Jasinski, M.J. (2002); Surface Water Dynamics in the Amazon Basin: Application of Satellite Radar Altimetry. Journal of Geophysical Research 107, http://dx.doi.org/10.1029/2001JD000609.

Boergens, E., Dettmering, D., Schwatke, C., Seitz, F. (2016); Treating the Hooking Effect in Satellite Altimetry Data: A Case Study along the Mekong River and Its Tributaries. Remote Sens., 8, 91, http://dx.doi.org/10.3390/rs8020091.

Bremner, J., Lopez-Carr, D., Zvoleff, A. (2013); Using new methods and data to assess and address population, fertility, and environment links in the Lake Victoria Basin, Population and the environment, Session 247, https://www.iussp.org/en/event/17/programme/paper/6136.

Brown, G.S. (1977); The Average Impulse Response of a Rough Surface and Its Applications. IEEE Transactions on Antennas and Propagation 25: 67-74. 
Calmant, S., Seyler, F., Cretaux, J.F. (2008); Monitoring Continental Surface Waters by Satellite Altimetry. Surveys in Geophysics 29, http://dx.doi.org/10.1007/s10712-008-9051-1.

Chamberlain, J.M., Bain, C.L., Boyd, D.F.A., McCourt, K., Butcher, T. and Palmer, S. (2014); Forecasting storms over Lake Victoria using a high resolution model. Met. Apps, 21: 419-430. http://dx.doi.org/10.1002/met.1403.

Chen, M., Xie, P., Janowiak, J.E., Arkin, P.A. (2002); Global land precipitation: A 50-yr monthly analysis based on gauge observations. Journal of Hydrometeorology, 3, 249ầ '266.

Cheng, M.K., Tapley, B.D. (2004); Variations in the Earth's oblateness during the past 28 years. Journal of Geophysical Research, Solid Earth, 109, B09402. http://dx.doi.org/10.1029/2004JB003028.

Consulate General of Ethiopia, (2012); Grand Ethiopian Renaissance Dam, Los Angeles, CA.

Conway, D. (2002); Extreme Rainfall Events and Lake Level Changes in East Africa: Recent Events and Historical Precedents. In E.O. Odada and D. O. Olago (eds.) The East African Great Lakes: Limnology, Palaeolimnology and Biodiversity. Advances in Global Change Research V. 12. Kluwer, Dordrecht. Pp. 63-92.

Crataux, J-F., Abarca-del-RAo, R., Berga-Nguyen, M., Arsen, A., Drolon, V., Clos, G., Maisongrande, P. (2016); Lake volume monitoring from space surveys. Geophysics 37:269-305. http://dx.doi.org/10.1007/s10712-016-9362-6.

Davis, C.H. (1995); Growth of the Greenland Ice Sheet: A Performance Assessment of Altimeter Retracking Algorithms. IEEE Transactions on Geo-Science and Remote Sensing 33 (5): 11081116, http://dx.doi.org/10.1109/36.469474.

Davis, C. H. (1997); A Robust Threshold Retracking Algorithm for Measuring Ice-Sheet Surface Elevation Change from Satellite Radar Altimeters. IEEE Transactions on Geoscience and Remote Sensing 35 (4), http://dx.doi.org/10.1109/36.602540.

Frappart, F., Calmant, S., Cauhope, M., Seyler, F., Cazenave, A. (2006); Preliminary results of envisat ra-2-derived water levels validation over the amazon basin, Remote Sensing of Environment, 100(2), 252-264. 
Gomez-Enri, J., Vignudelli, S., Quartly, G., Gommenginger, C., Benveniste, J. (2009); Bringing Satellite Radar Altimetry Closer to Shore. Remote Sensing, SPIE Newsroom, http://dx.doi.org/10.1117/2.1200908.1797.

Hassan, A.A., Jin, S. (2014); Lake level change and total water discharge in East Africa Rift Valley from satellite-based observations, In Global and Planetary Change, Volume 117, Pages 79-90, ISSN 0921-8181, https://doi.org/10.1016/j.gloplacha.2014.03.005.

Huffman, G.J., Adler, R.F., Bolvin, D.T., Gu, G., Nelkin, E.J., Bowman, K.P., Hong, Y., Stocker, E.F., Wolff, D.B. (2007); The TRMM Multi-satellite Precipitation Analysis: QuasiGlobal, Multi-Year, Combined-Sensor Precipitation Estimates at Fine Scale. J. Hydrometeor., $8(1), 38-55$.

Ismail, S.S., Samuel, M.G. (2011); Response of river Nile dredging on water levels. Fifteenth International Water Technology Conference, IWTC-15 2011, Alexandria, Egypt.

Khaki, M., Forootan, E., Sharifi, M.A. (2014); Satellite radar altimetry waveform retracking over the Caspian Sea. Int. J. Remote Sens., 35(17), 6329-6356, http://dx.doi.org/10.1080/01431161.2014.951741.

Khaki, M., Forootan, E., Sharifi, M.A., Awange, J., Kuhn, M. (2015); Improved gravity anomaly fields from retracked multimission satellite radar altimetry observations over the Persian Gulf and the Caspian Sea. Geophys. J. Int. 202 (3): 1522-1534, http://dx.doi.org/10.1093/gji/ggv240.

Khaki, M., Ait-El-Fquih, B., Hoteit, I., Forootan, E., Awange, J., Kuhn, M., (2017a); A Two-update Ensemble Kalman Filter for Land Hydrological Data Assimilation with an Uncertain Constraint, Journal of Hydrology, ISSN 0022-1694, https://doi.org/10.1016/j.jhydrol.2017.10.032.

Khaki, M., Hoteit, I., Kuhn, M., Awange, J., Forootan, E., van Dijk, A.I.J.M., Schumacher, M., Pattiaratchi, C. (2017b); Assessing sequential data assimilation techniques for integrating GRACE data into a hydrological model, Advances in Water Resources, Volume 107, Pages 301-316, ISSN 0309-1708, http://dx.doi.org/10.1016/j.advwatres.2017.07.001.

Khaki, M., Schumacher, M., J., Forootan, Kuhn, M., Awange, E., van Dijk, A.I.J.M. (2017c); Accounting for Spatial Correlation Errors in the Assimilation of GRACE into Hydrological 
Models through localization, Advances in Water Resources, Available online 1 August 2017, ISSN 0309-1708, https://doi.org/10.1016/j.advwatres.2017.07.024.

Khaki, M., Awange, J., Forootan, E.,Kuhn, M. (2018a); Understanding the association between climate variability and the Nile's water level fluctuations and water storage changes during 1992-2016, Science of The Total Environment, Volume 645, Pages 1509-1521, ISSN 00489697, https://doi.org/10.1016/j.scitotenv.2018.07.212.

Khaki, M., Ait-El-Fquih, B., Hoteit, I., Forootan, E., Awange, J., Kuhn, M., (2018b); Unsupervised ensemble Kalman filtering with an uncertain constraint for land hydrological data assimilation, Journal of Hydrology, Volume 564, Pages 175-190, ISSN 0022-1694, https://doi.org/10.1016/j.jhydrol.2018.06.080.

Khaki, M., Forootan, E., Kuhn, M., Awange, J., Longuevergne, L., Wada, W., (2018c); Efficient Basin Scale Filtering of GRACE Satellite Products, In Remote Sensing of Environment, Volume 204, 2018, Pages 76-93, ISSN 0034-4257, https://doi.org/10.1016/j.rse.2017.10.040.

Khan, S. I., Adhikari, P., Hong, Y., Vergara, H., F Adler, R., Policelli, F., Irwin, D., Korme, T., Okello, L. (2011); Hydroclimatology of Lake Victoria region using hydrologic model and satellite remote sensing data, Hydrol. Earth Syst. Sci., 15, 107-117, https://doi.org/10.5194/hess$15-107-2011$.

Kite, G.W. (1982); Analysis of Lake Victoria levels. Hydrological Sciences Journal, 27(2,6), 99-110.

Kizza, M., Rodhe, A., Xu, C.Y., Natle, K.H., Halldian, S., (2009); Temporal rainfall variability in the Lake Victoria Basin in east Africa during the twentieth century Theor. Appl. Climatol., 98, pp. 119-135

Lorenz, E. (1956); Empirical orthogonal function and statistical weather prediction. Technical Report Science Report No 1, Statistical Forecasting Project. MIT, Cambridge.

Martin, T.V., Zwally, H., Brenner, A.C., Bindschadler, R.A. (1983); Analysis and Retracking of Continental Ice Sheet Radar Altimeter Waveforms. Journal of Geophysical Research 88 (C3): 1608, http://dx.doi.org/10.1029/JC088iC03p01608. 
Mayer-Gürr, T., Zehentner, N., Klinger, B., Kvas, A. (2014); ITSG-Grace2014: a new GRACE gravity field release computed in Graz. - in: GRACE Science Team Meeting (GSTM), Potsdam am: 29.09.2014.

Miralles, D.G., Holmes, T.R.H., de Jeu, R.A.M., Gash, J.H., Meesters, A.G.C.A., Dolman, A.J. (2011); Global land-surface evaporation estimated from satellite-based observations, Hydrology and Earth System Sciences, 15, 453-469.

Mohamed, Y.A., van den Hurk, B.J.J.M., Savenije, H.H.G., Bastiaanssen, W.G.M. (2005); Impact of the Sudd wetland on the Nile hydroclimatology, Water Resour. Res., 41, W08420, http://dx.doi.org/10.1029/2004WR003792.

Mu, Q., Heinsch, F.A., Zhao, M., Running, S.W. (2007); Development of a global evapotranspiration algorithm based on MODIS and global meteorology data. Remote Sensing of Environment 111, 519-536, http://dx.doi.org/10.1016/j.rse.2007.04.015.

Mu, Q., Zhao, M., Running, S.W. (2011); Improvements to a MODIS Global Terrestrial Evapotranspiration Algorithm. Remote Sensing of Environment 115: 1781-1800.

Mugidde, R., Hecky, R.E., Hendzel, L.L., Taylor, W.D. (2003); Pelagic Nitrogen Fixation in Lake Victoria (East Africa). J Great Lakes Res 29(2): 76-88.R. MugiddeRE HeckyLL HendzelWD Taylor2003Pelagic Nitrogen Fixation in Lake Victoria (East Africa).J Great Lakes Res2927688.

Munier, S., Aires, F., Schlaffer, S., Prigent, C., Papa, F., et al. (2015); Combining datasets of satellite retrieved products for basin-scale water balance study. Part II: Evaluation on the Mississippi Basin and closure correction model. Journal of Geophysical Research: Atmospheres, American Geophysical Union, 2014, 119, pp.100-116.

Nicholson, S.E., Yin, X. (2001); Rainfall conditions in equatorial East Africa during the nineteenth century as inferred from the record of Lake Victoria. Climatic Change, 48(2-3), 387-398

Nicholson, S.E., Some, B., Mccollum, J., Nelkin, E., Klotter, D., Berte, Y., Diallo, B.B., Gaye, I., Kpabeba, G., Ndiaye, O., Noukpozounkou, J.N., Tanu, M.M., Thiam, A., Toure, A.A., Traore, A.K. (2003); Validation of TRMM and other rainfall estimates with a high-density gauge dataset for West Africa. Part II: validation of TRMM rainfall products. J. Appl. Meteor. $42,1355-1368$. 
Njuru, P.G. (2014); An overview of the present status of Water Quality of Lake Victoria, Kenya: a limnological perspective, Ministry of Environment and Natural Resources, LVEMP Water Quality Component Kisumu, Kenya, http://hdl.handle.net/1834/6970.

Okungu, J.O., Njoka, S., Abuodha, J.O.Z., Hecky, R.E. (2005); An introduction to Lake Victoria catchment, water quality, physical limnology and ecosystem status (Kenyan sector). Lake Victoria Environment Management Project (LVEMP) Kisumu, Kenya, http://hdl.handle.net/1834/7140.

Omondi, P., Awange, J.L., Ogallo, L.A., Ininda, J., Forootan, E. (2013); The influence of low frequency sea surface temperature modes on delineated decadal rainfall zones in Eastern Africa region. Advances in Water Resources. 54: pp. 161-180.

Omondi, P. A., Awange, J. L., Forootan, E., Ogallo, L. A., Barakiza, R., Girmaw, G. B., Fesseha, I., Kululetera, V., Kilembe, C., Mbati, M. M., Kilavi, M., King'uyu, S. M., Omeny, P. A., Njogu, A., Badr, E. M., Musa, T. A., Muchiri, P., Bamanya, D. and Komutunga, E. (2014); Changes in temperature and precipitation extremes over the Greater Horn of Africa region from 1961 to 2010. Int. J. Climatol., 34: 1262-1277. http://dx.doi.org/10.1002/joc.3763.

Onganga, O., Awange, J.L. (2005); Lake Victoria. ecology, resources, environment, World Lakes Conference. 11. 31 Oct.-4 Nov. 2005. Nairobi. KE.

Owor, M., Taylor, R., Mukwaya, C., et al. (2011); Groundwater - surface water interactions on deeply weathered surfaces of low relief in the Upper Nile Basin of Uganda. Hydrogeol J., 19: 1403. https://doi.org/10.1007/s10040-011-0779-1.

Pan, M., Wood, E.F. (2006); Data assimilation for estimating the terrestrial water budget using a constrained ensemble Kalman filter. Journal of Hydrometeorology, 7 (3), 534-547.

Pan, M., Sahoo, A.K., Troy, T.J., Vinukollu, R.K., Sheffield, J., Wood, E.F. (2012); Multisource Estimation of Long-Term Terrestrial Water Budget for Major Global River Basins. Journal of Climate, 25 (9), 3191-3206.

Preisendorfer, R.W. (1988); Principal Component Analysis in Meteorology and Oceanography. Elsevier, New York, 425 pp. 
Piper, B.S., Plinston, D.T., Sutcliffe, J.V. (1986); The water balance of Lake Victoria. Hydrol. Sci. J. 31 (1), 25-37.

Sahoo, A.K., Pan, M., Troy, T.J., Vinukollu, R.K., Sheffield, J., Wood, E.F. (2011); Reconciling the global terrestrial water budget using satellite remote sensing. Remote Sensing of Environment, 115 (8), 1850-1865.

Samuel, M.G. (2014); Limitations of navigation through Nubaria canal, Egypt. Journal of Advanced Research, 5, 147-155, http://dx.doi.org/10.1016/j.jare.2013.01.006.

Schneider, U., Fuchs, T., Meyer-Christoffer, A., Rudolf, B. (2008); In G. P. C. Centre (Ed.), Internet publication.

Sene, K.J., Plintson, D.T. (1994); A review and update of the hydrology of Lake Victoria in East Africa. Hydrological Sciences Journal, 50(1-2), 177-208.

Seyler, F., Calmant, S., Santos da Silva, J., Filizola, N., Roux, E., Cochonneau, G., Vauchel, P., Bonnet, M.-P. (2008); Monitoring water level in large trans-boundary ungauged basins with altimetry: the example of ENVISAT over the Amazon basin. Journal of Applied Remote Sensing, 7150: 715017, http://dx.doi.org/10.1117/12.813258.

Sichangi, A.W., Makokha, G.O. (2017); Monitoring water depth, surface area and volume changes in Lake Victoria: integrating the bathymetry map and remote sensing data during 1993-2016, Modeling Earth Systems and Environment, 3:533-538, http://dx.doi.org/10.1007/s40808-017-0311-2.

Simmons, A. J., Uppala, S., Dee, D., Kobayashi, S. (2007); ERA-interim: New ECMWF reanalysis products from 1989 onwards, ECMWF Newsletter No. 110, Winter 2006/07.

Song, C., Huang, B., Ke, L. (2015); Heterogeneous change patterns of water level for inland lakes in High Mountain Asia derived from multi-mission satellite altimetry. Hydrol Processes 29:2769-2781, http://dx.doi.org/10.1002/hyp.10399.

Swenson, S., Wahr, J. (2002); Methods for inferring regional surface-mass anomalies from Gravity Recovery and Climate Experiment (GRACE) measurements of time-variable gravity. Journal of Geophysical research, 107, B9, 2193. http://dx.doi.org/10.1029/2001JB000576. 
Swenson, S., Wahr, J. (2006); Post-processing removal of correlated errors in GRACE data. Geophysical Research Letters, 33, L08402. http://dx.doi.org/10.1029/2005GL025285.

Swenson, S., Chambers, D., Wahr, J. (2008); Estimating geocentervariations from a combination of GRACE and ocean model output. Journal of Geophysical research, 113, B08410. http://dx.doi.org/10.1029/2007JB005338.

Swenson, S., Wahr, J. (2009); Monitoring the water balance of Lake Victoria, East Africa, from space. Journal of Hydrology, 370, 163-176, http://dx.doi.org/10.1016/j.jhydrol.2009.03.008.

Tropical Rainfall Measuring Mission (TRMM) (2011); TRMM (TMPA/3B43) Rainfall Estimate L3 1 month 0.25 degree x 0.25 degree V7, Greenbelt, MD, Goddard Earth Sciences Data and Information Services Center (GES DISC), Accessed [Data Access Date] https://disc.gsfc.nasa.gov/datacollection/TRMM_3B43_7.html.

Tseng, K.H., Shum, C.K., Yi, Y., Fok, H.S., Kuo, C.Y., Lee, H., Cheng, X., Wang, X. (2013); Envisat Altimetry Radar Waveform Retracking of Quasi-Specular Echoes over the Ice-Covered Qinghai Lake. Terrestrial Atmospheric and Oceanic Science 24: 615-627, http://dx.doi.org/10.3319/TAO.2012.12.03.01(TibXS).

Uebbing, B., Kusche, J., Forootan, E. (2015); Waveform retracking for improving level estimations from Topex/Poseidon, Jason-1 and -2 altimetry observations over African lakes, IEEE Trans. Geosci. Remote Sens., 53(4), 2211-2224.

Wahr, J.M., Molenaar, M., Bryan, F. (1998); Time variability of the Earth's gravity field: hydrological and oceanic effects and their possible detection using GRACE. J Geophys Res 108(B12):30205-30229, http://dx.doi.org/10.1029/98JB02844.

Wingham, D.J., Rapley, C.G., Griffiths, H. (1986); New Techniques in Satellite Altimeter Tracking Systems, ESA Proceedings of the 1986 International Geoscience and Remote Sensing Symposium (IGARSS 86) on Remote Sensing. Todays Solutions for Tomorrows Information Needs 3: 1339-1344.

Woodward, G., Warren, P.H. (2007); Body size and predatory interactions in freshwaters: scaling from individuals to communities. In Body size: the structure and function of aquatic ecosystems (eds Hildrew A. G., Raffaelli D., Edmonds-Brown R., editors. ), pp. 98-117 Cambridge, UK: Cambridge University Press. 
${ }_{627}$ Yin, X., Nicholson, S.E. (1998); The water balance of Lake Victoria. Hydrol. Sci. - J. Sci. Hydrol. 43 (5), 789-811. 